\title{
Derris Indica Leaves Extract as a Green Inhibitor for the Corrosion of Aluminium in Alkaline Medium
}

\author{
Neha K. Nambiar, ${ }^{1,2}$ D. Brindha, ${ }^{3}$ Parthipan Punniyakotti, ${ }^{1}$ B.R. Venkatraman ${ }^{3}$ and Subramania Angaiah ${ }^{1, *}$
}

\begin{abstract}
The corrosion inhibitive effect of Derris indica leaves extract (DILE) on aluminium in $1 \mathrm{M} \mathrm{NaOH}$ is investigated at different temperatures. For this purpose, weight loss studies and electrochemical methods including potentiodynamic polarization (PDP) and electrochemical impedance spectroscopy (EIS) techniques are employed. Surface analysis of the treated and untreated aluminium coupons is done by using metallurgical microscopy. About $60.2 \%$ of maximum corrosion inhibition efficiency is attained with an optimum inhibitor concentration of $1.2 \mathrm{~g} / \mathrm{L}$. Both weight loss and electrochemical studies confirmed that DILE plays a crucial role in the formation of a protective layer over metal surfaces. Also, electrochemical measurements revealed that DILE behaves as a mixed type of corrosion inhibitor. The kinetic parameters and thermodynamic parameters are calculated using Arrhenius theory and transition state theory. Langmuir adsorption isotherm was found to be the best fit and physical adsorption mechanism was proposed.
\end{abstract}

Keywords: Green inhibitors; Aluminium corrosion; Derris indica; Potentiodynamic polarization studies.

Received: 22 January 2021; Revised: 25 September 2021; Accepted: 01 October 2021.

Article type: Research article.

\section{Introduction}

Aluminium is the third most abundant element/metal on the earth's crust. It is mostly found in the form of its oxide known as bauxite. Aluminium has several useful properties which make it an important and useful metal. Some of the key properties of aluminum are: it is ductile, malleable, and light, an excellent conductor of heat and electricity, highly reflective, non-ferromagnetic, retains its strength at low temperatures, and is often used in cryogenic applications. Due to its useful properties and abundance, aluminum finds wide applications in various industries such as automotive, aerospace, construction, and electrical power generation. ${ }^{[1]}$ In specific, one notable application of aluminium is in aluminium-air batteries due to its high energy density $\left(8.1 \mathrm{~kW} \mathrm{~h} \mathrm{~kg}^{-1}\right)$ and electrode potential of $2.35 \mathrm{~V}$ ( $v$ s. standard hydrogen electrode) in an alkaline medium. ${ }^{[2,3]}$

Among various types of corrosion observed in aluminium,

${ }^{1}$ Electro-Materials Research Laboratory, Centre for Nanoscience and Technology, Pondicherry University, Puducherry-605014, India.

2 Department of Chemistry, CHRIST (Deemed to be University), Bengaluru-560029, India.

${ }^{3} P G$ \& Research Dept. of Chemistry, Periyar EVR College, Trichy620023, India.

*Email: a.subramania@gmail.com (A. Subramania) pitting corrosion is observed under stagnant conditions of the corrosion medium. ${ }^{[4]}$ Pitting corrosion is a type of corrosion, in which pits/holes are locally formed on the surface of the aluminium. Naturally, aluminium resists the corrosion process by forming a passive oxide layer on its surface upon exposure to freshwater, seawater, soil, and corrosive chemicals. This oxide layer is stable in the $\mathrm{pH}$ range of 4-9 but becomes soluble in strong acid and alkaline media, which leads to the dissolution of the metal. ${ }^{[5]}$

This is detrimental to the life of the aluminium-air battery, which often employs alkaline media as an electrolyte, and can sometimes cause an explosion due to the hydrogen build-up. ${ }^{\left[{ }^{[6]}\right.}$ Corrosion problems make a huge impact on the gross national product of all developed and developing countries and are associated with safety concerns as well. Hence, corrosioncontrolling methods are gaining huge attention among the scientific and industrial communities.

The use of corrosion inhibitors is one of the promising approaches to reducing aluminium corrosion in an alkaline medium. Many researchers have used several organic and inorganic compounds to inhibit the corrosion problems, which include [3-(4-hydroxy-3-methoxy-phenyl)- 1-(2hydroxyPhenyl-propenone)], ${ }^{[7]}$ thiourea derivatives, ${ }^{\left[{ }^{[8]}\right.} \mathrm{N}$ thiazolyl-2-cyanoacetamide, ${ }^{[9]}$ 3-Methyl-4-amino-5mercapto- 1,2,4-triazole, ${ }^{[10]}$ Tween $80,{ }^{[11]}$ etc. Apart from corrosion inhibition characteristics, these compounds are 
considered hazardous, expensive, and harmful to the environment as well as to human beings. These shortcomings make a way for cost-effective, green, and sustainable inhibitors with an environment-friendly nature.

Plant extracts are rich in phytochemicals such as flavonoids, alkaloids, tannins, saponins, amino acids and phenols, and other organic compounds. They contain heteroatoms such as $\mathrm{N}, \mathrm{O}, \mathrm{S}$, and $\pi$ electron centers, through which they can interact with the metal surface and adsorb over it. ${ }^{[12,13]}$ Thus, they can serve as efficient corrosion inhibitors for aluminium in acidic and alkaline mediums.

To formulate an efficient corrosion inhibitor that is selective to different regions, it is necessary to explore different plants and their parts. To date, different researchers have studied the aptitude of different plants as corrosion inhibitors for aluminium corrosion in alkaline medium. For example, Chaubey et al. ${ }^{[1]}$ have studied the inhibitive properties of Kalmegh leaf extract on aluminium alloy corrosion in $1 \mathrm{M} \mathrm{NaOH}$ and found a maximum inhibition efficiency of $82 \%$. In another study, Geetha et al. ${ }^{[2]}$ used Solanum trilobatum leaves extract as a corrosion inhibitor for aluminium in $1 \mathrm{M} \mathrm{NaOH}$ and found a maximum inhibition efficiency of 93\%. Abiola and Otaigbe ${ }^{[14]}$ used Phyllanthus amarus leaves extract as an aluminium corrosion inhibitor in $2 \mathrm{M} \mathrm{NaOH}$ and found $76 \%$ of corrosion inhibition efficiency with $20 \% \mathrm{v} / \mathrm{v}$ of inhibitor concentration. Sirajunnisa et al. ${ }^{[15}$ used Ziziphus jujuba leaves extract as a green corrosion inhibitor for aluminium corrosion in $1 \mathrm{~N} \mathrm{NaOH}$ and obtained about $76 \%$ of inhibition efficiency. Umoren et al. ${ }^{[16]}$ tested Vigna unguiculata as a corrosion inhibitor for aluminium in alkaline and acidic conditions, and a maximum inhibition efficiency of $79.63 \%$ was observed in $0.5 \mathrm{M} \mathrm{NaOH}$. Similarly, Chaubey et al. ${ }^{[17]}$ used Neolamarkia cadamba bark extract as an aluminium corrosion inhibitor in $1 \mathrm{M} \mathrm{NaOH}$ and found $87 \%$ of inhibition efficiency. Abdallah et al ${ }^{[18]}$ studied gelatin as a green inhibitor for aluminium and aluminium silicon alloys in $0.1 \mathrm{M} \mathrm{NaOH}$. Interestingly, Obot and Obi-Egbedi ${ }^{[19]}$ found corrosion inhibition activity with Ipomoea involcrata in $1 \mathrm{M}$ $\mathrm{NaOH}$, and Ambrish ${ }^{[20]}$ found corrosion inhibition activity of Trachyspermum copticum seed extract for aluminium in $0.5 \mathrm{M}$ $\mathrm{NaOH}$ solution. Recently, Xhanari et al. ${ }^{[21]}$ gave a detailed review of green corrosion inhibitors which have been used to control the corrosion of aluminium and its alloys in different corrosive media. Abdallah et al. ${ }^{[22]}$ investigated the effectiveness of animal glue as a corrosion inhibitor for aluminium and its alloys in $0.1 \mathrm{M} \mathrm{NaOH}$. Similarly, Eid et $a l .{ }^{[23]}$ observed methyl cellulose to exhibit corrosion inhibition action for aluminium and aluminium-silicon alloys in $0.1 \mathrm{M}$ $\mathrm{NaOH}$.

In the present investigation, Derris indica leaves extract (DILE) is used as a corrosion inhibitor for aluminium in $1 \mathrm{M}$ $\mathrm{NaOH}$ solution under stagnant conditions. To the best of our knowledge, there is no report on the use of DILE as a corrosion inhibitor for aluminium in an alkaline medium. The corrosion inhibition efficiency is studied by chemical (weight loss, WL) and electrochemical (PDP and EIS) measurements. Insight into the corrosion mechanism is obtained by fitting relevant adsorption isotherms and the effect of temperature on the inhibition efficiency is also studied. Metallurgical microscopic study is used to observe the changes that have occurred during the corrosion inhibition studies.

\section{Experimental}

\subsection{Materials preparation}

Rectangular size aluminium coupons with dimensions of $5 \times$ $1 \times 0.2 \mathrm{~cm}$ were used for weight loss studies. Each coupon was polished with different grades of waterproof abrasive paper to remove embedded impurities. The coupons were then washed with distilled water, wiped with acetone, and finally dried before carrying out the experiments. A freshly polished coupon was used for each experiment. The aluminium coupons with a $1 \mathrm{~cm}^{2}$ exposed area were used as the working electrode for electrochemical studies. The coupons were polished using the same procedure as stated above. For entire experiments, $1 \mathrm{M} \mathrm{NaOH}$ was prepared using double distilled water and stored for further use.

\subsection{Preparation of Derris indica leaves extract (DILE)}

Fresh leaves of Derris indica were collected at Pondicherry University campus, Puducherry India, and washed with tap water followed by distilled water. The leaves were dried in a hot air oven for $6 \mathrm{~h}$ at $50{ }^{\circ} \mathrm{C}$ and then ground into a fine powder. $10 \mathrm{~g}$ of this powder was refluxed in $100 \mathrm{~mL}$ water for 2 hours. The refluxed solution was filtered using No.1 Whatman filter paper and heated in a water bath to evaporate the water content until a dried component was obtained. ${ }^{[15,24]}$ For the preparation of DILE inhibitor, dried extract of about 30,60, 90, and 120 mg was used in $100 \mathrm{~mL}$ of $1 \mathrm{M} \mathrm{NaOH}$ to obtain $300,600,900$, and $1200 \mathrm{ppm}$ of $(0.3,0.6,0.9$, and $1.2 \mathrm{~g} / \mathrm{L})$ concentrations for corrosion studies.

\subsection{Weight loss studies}

The procedure adopted for weight loss measurements was similar to that reported earlier. ${ }^{[25-27]}$ The previously weighed aluminium coupons were immersed in the pre-prepared $1 \mathrm{M}$ $\mathrm{NaOH}$ solution with the help of glass hooks. The coupons were taken out after 2 hours. The coupons were rinsed with distilled water to remove the inhibitor solution and then rinsed with acetone to remove the corrosion product. The washed coupons were dried and reweighed using an electronic balance to obtain the final weight of the coupons. The weight lost during the experiment was calculated by finding the difference between the initial and final weights. The corrosion rate and inhibition efficiency were calculated using Equations (1) and (2), respectively:[28]

$$
\text { Corrosion rate }(\mathrm{mmpy})=\frac{8.76 \times 10^{4} \times W}{D A T}
$$

where $W=$ weight loss in grams, $A=$ Area in square $\mathrm{cm}, T=$ Time in hours, $D=$ Density of aluminium in $\mathrm{gm} / \mathrm{cm}^{3}(2.70)$.

Inhibition efficiency $(\%)=\left(\left(W_{B}-W_{I}\right) / W_{B}\right) \times 100$ 
where $W_{B}$ and $W_{I}$ are weight loss in the absence and presence of the inhibitor.

The degree of surface coverage $(\theta)$ was calculated from the weight loss measurements using Equation (3):

$$
\text { Surface coverage }(\theta)=\left(W_{B}-W_{I}\right) / W_{B}
$$

where $W_{B}$ and $W_{I}$ are the weight loss in the absence and presence of the inhibitor.

The effect of temperature on the inhibition efficiency of the inhibitor was studied to carry out weight loss measurements in the temperature ranging from 303-333 K.

\subsection{Electrochemical studies}

Electrochemical experiments were performed in a conventional three-electrode setup connected to a Biologic electrochemical workstation. An Aluminium coupon with a 1 $\mathrm{cm}^{2}$ exposure area was used as a working electrode, platinum was used as the counter electrode and a standard calomel electrode (SCE) was used as a reference. All the experiments were carried out after reaching a stable open circuit potential $\left(E_{o c}\right)$ upon immersion of the aluminium strip in the corrosion medium. The AC-impedance spectra were recorded in the frequency range between $100 \mathrm{kHz}$ to $1 \mathrm{~Hz}$ at an $\mathrm{AC}$ amplitude of $10 \mathrm{mV}$. The impedance parameters were obtained by fitting with an equivalent circuit model (Fig. 1) using EC lab software, where $\mathrm{R} 1$ is solution resistance $\left(R_{S}\right), \mathrm{C} 1$ corresponds to the capacitance of the double layer $\left(C_{d l}\right), \mathrm{R} 2$ corresponds to the charge transfer resistance $\left(R_{c t}\right)$. The inhibition efficiency was calculated from the $R_{c t}$ values using Equation (4): ${ }^{[29]}$

$$
I E(\%)=\frac{R_{c t}-R_{c t}^{*}}{R_{c t}} \times 100
$$

where $R_{c t}^{*}$ and $R_{c t}$ are the charge transfer resistance values in the absence and presence of the inhibitor, respectively.

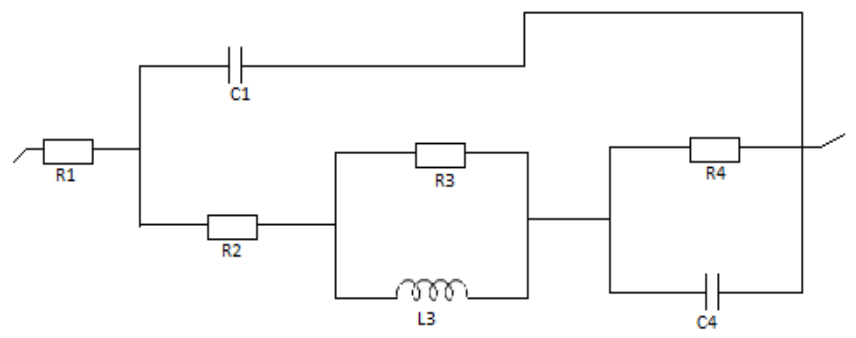

Fig. 1 Electrical equivalent circuit used for the analysis of impedance spectra.

Potentiodynamic polarization curves were recorded in the potential range between $\pm 250 \mathrm{mV}$ from open circuit potential $\left(E_{o c}\right)$. The measurements were made by automatically changing the electrode potential from $-1.850 \mathrm{~V}$ to $-1.350 \mathrm{~V}$ at a scan rate of $25 \mathrm{mVs}^{-1}$. The linear Tafel segments of anodic and cathodic curves were extrapolated to the corrosion potential $\left(E_{c o r r}\right)$ to obtain corrosion current densities $\left(I_{\text {corr }}\right)$. This was done using EC lab software.

The inhibition efficiency was calculated using the Equation
$(5):[29]$

$$
I E(\%)=\frac{\left(I_{\text {corr }}^{*}-I_{\text {corr }}\right)}{I_{\text {corr }}^{*}} \times 100
$$

where $I_{\text {corr }}^{*}$ and $I_{\text {corr }}$ are the corrosion current densities in the absence and presence of the inhibitor, respectively.

\subsection{Metallurgical microscopic study}

The aluminium coupons before and after immersion were retrieved, washed, and dried. The surface changes were monitored by using metallurgical microscopy.

\section{Results and discussion}

3.1 Weight loss studies

The weight loss results obtained for the aluminium coupons during the corrosion experiments in $1 \mathrm{M} \mathrm{NaOH}$ with and without DILE are presented in Table 1. From Table 1, it is clear that with an increase in DILE concentration, the weight loss and corrosion rate were decreased, which revealed that an increase in inhibition efficiency is directly proportional to an increase in the inhibitor concentration. The increase in inhibition efficiency can be attributed to the increase in the adsorbed inhibitor molecules on the metal surface resulting in higher surface coverage. ${ }^{[30]}$ The adsorbed molecules form a film over the corroding metal, which reduces the surface area available for the attack of aggressive $\mathrm{OH}^{-}$ions from the alkaline solution. This results in a decrease in corrosion rate and a consequent increase in inhibition efficiency. ${ }^{[31]}$

Table 1. Corrosion parameters obtained from weight loss measurements for aluminium in $1 \mathrm{M} \mathrm{NaOH}$ containing different concentrations of DILE.

\begin{tabular}{ccccc}
\hline $\begin{array}{c}\text { Conc. of } \\
\text { DILE } \\
(\mathrm{ppm})\end{array}$ & $\begin{array}{c}\text { Weight } \\
\text { loss } \\
\left(\mathrm{g} / \mathrm{cm}^{2}\right)\end{array}$ & $\begin{array}{c}\text { Corrosion } \\
\text { rate } \\
(\mathrm{mmpy})\end{array}$ & $\begin{array}{c}\text { Inhibition } \\
\text { efficiency } \\
(\%)\end{array}$ & $\begin{array}{c}\text { Surface } \\
\text { coverage } \\
(\theta)\end{array}$ \\
\hline Blank & 0.2625 & 823.73 & - & - \\
300 & 0.1640 & 514.50 & 37.5 & 0.375 \\
600 & 0.1394 & 437.56 & 46.9 & 0.469 \\
900 & 0.1214 & 380.89 & 53.8 & 0.538 \\
1200 & 0.1056 & 331.32 & 59.8 & 0.598 \\
\hline
\end{tabular}

\subsection{Effect of temperature on corrosion inhibition}

The effect of temperature on the aluminium corrosion in the presence of different concentrations of DILE was studied in the temperature range of 303 to $313 \mathrm{~K}$ by weight loss measurements. The experiment was carried out for an immersion period of 2 hours and the freshly polished coupons were used in each turn. The variation of the inhibition efficiency with concentrations of the inhibitor in the temperature range from $303-313 \mathrm{~K}$ is shown in Table 2. Temperature influences the structure and thickness of the DILE film adsorbed on aluminium. An increase in temperature lowers the inhibition efficiency, thereby indicating that DILE is adsorbed on aluminium through physisorption. This can be attributed to the desorption of adsorbed inhibitor molecules from the surface of the aluminium at a higher temperature. ${ }^{[17,32]}$ 
Table 2. Effect of temperature on the inhibition efficiency of DILE for aluminium corrosion in $1 \mathrm{M} \mathrm{NaOH}$ solution.

\begin{tabular}{ccccc}
\hline \multirow{2}{*}{$\begin{array}{c}\text { DILE Conc. } \\
(\mathrm{ppm})\end{array}$} & $303 \mathrm{~K}$ & $313 \mathrm{~K}$ & $323 \mathrm{~K}$ & $333 \mathrm{~K}$ \\
\cline { 2 - 5 } 300 & 37.5 & 29.3 & 20.1 & 15.5 \\
600 & 46.8 & 36.9 & 28.3 & 20.6 \\
900 & 53.7 & 42.1 & 35.8 & 24.9 \\
1200 & 59.7 & 49.4 & 40.6 & 29.3 \\
\hline
\end{tabular}

To have a better understanding of the effect of temperatures on the reaction, the activation parameters such as activation energy $\left(E_{a}\right)$, enthalpy of activation $(\Delta H)$, and the entropy of activation $(\triangle S)$ were calculated, which was done only for the blank solution and the optimum concentration of the inhibitor (1200 ppm).

The corrosion of aluminium obeys Arrhenius law in the studied temperature range. Using Arrhenius law, the corrosion rate can be expressed as shown in Equation (6): ${ }^{[33]}$

$$
\log C R=\log A-\frac{E_{a}}{2.303 R T}
$$

where $C R=$ Corrosion rate, $E_{a}=$ Activation energy for the corrosion process, $A=$ Arrhenius frequency factor, $R=$ Universal gas constant, and $T=$ Absolute temperature.

$E_{a}$ is calculated from the slope of the plot between the logarithm of $C R$ and the reciprocal of $T$ (Equation 7) is illustrated in Fig. 2.

$$
E_{a}=\text { slope } \times 2.303 \times R
$$

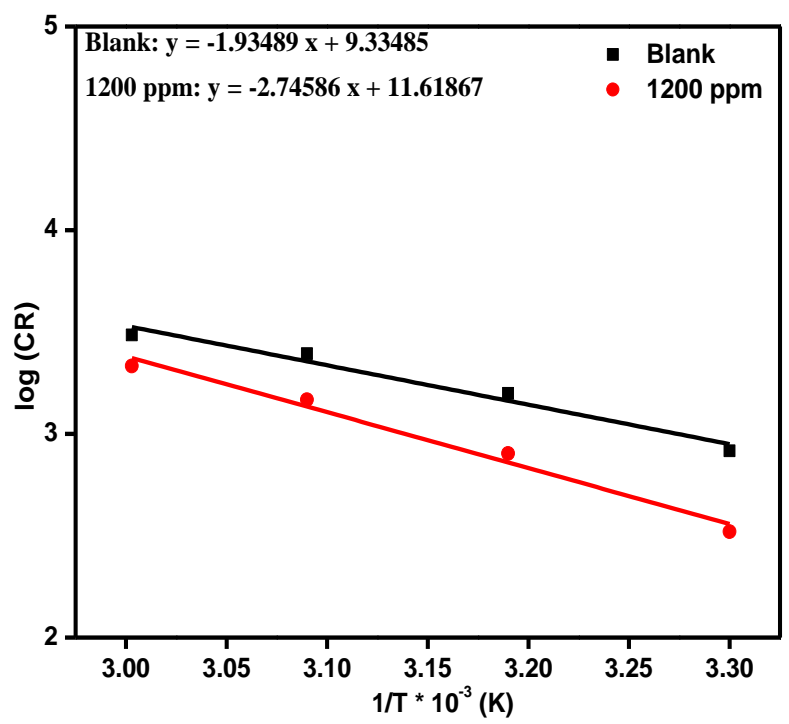

Fig. 2 Arrhenius plots for aluminium in $1 \mathrm{M} \mathrm{NaOH}$ in the absence and presence of the best concentration (1200 ppm) of DILE.

The Eyring transition state equation provides a relationship between the enthalpy of activation $(\Delta H)$, the entropy of activation $(\triangle S)$, and corrosion rate $(C R)$ and can be expressed as in Equation (8): ${ }^{[34]}$

$$
C R=\frac{R T}{N h} \exp \left(\frac{\Delta S}{R}\right) \exp \left(-\frac{\Delta H}{R T}\right)
$$

where $N=$ Avogadro's number $(6.023 \times 1023), h=$ Planck's constant $\left(6.626 \times 10^{-34} \mathrm{~J} \mathrm{~s}\right), \Delta H$ and $\Delta S$ are calculated from the slope (Equation (9)) and intercept (Equation (10)) of the line obtained from the plot of $\log C R / T$ vs $1 / T$ is illustrated in Fig. 3.

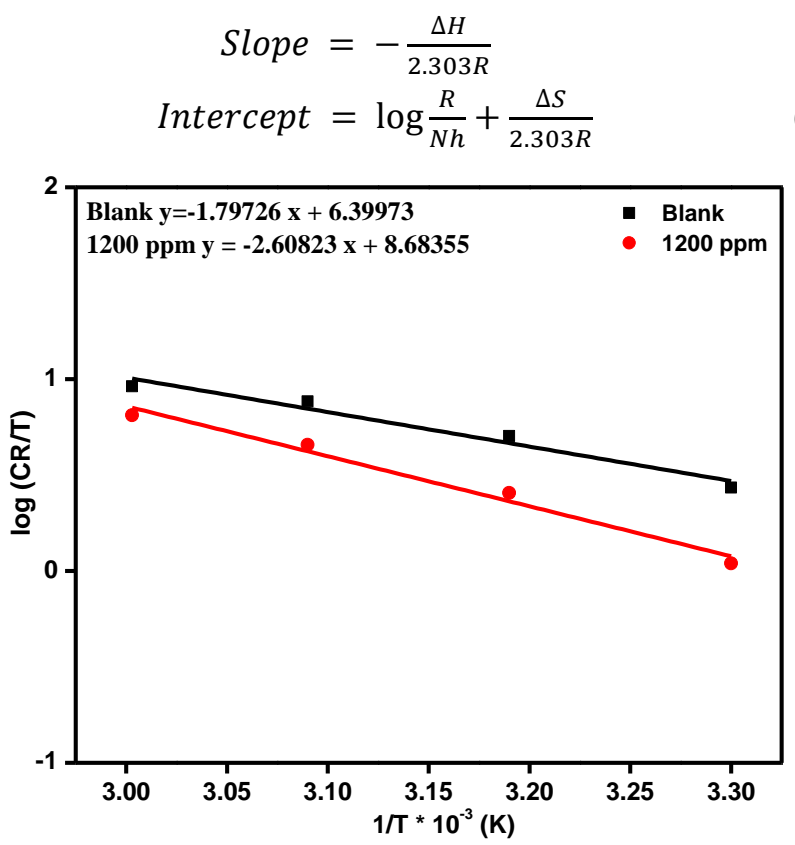

Fig. 3 Variation of $\log (C R / T)$ vs $(1 / T)$ for aluminium in $1 \mathrm{M}$ $\mathrm{NaOH}$ in the absence and presence of the best concentration (1200 ppm) of DILE.

The calculated values of the $E_{a}$ over the temperature range of 303-333 K are given in Table 3. It can be observed that the values of $E_{a}$ for the inhibitor solution are higher than that of the blank solution.

$\Delta H$ and $\Delta S$ are calculated from the slope and intercept of the line obtained from the plot of $\log C R / T$ versus $1 / T$ is illustrated in Fig. 3. The calculated values of $\Delta \mathrm{H}$ and $\Delta \mathrm{S}$ for

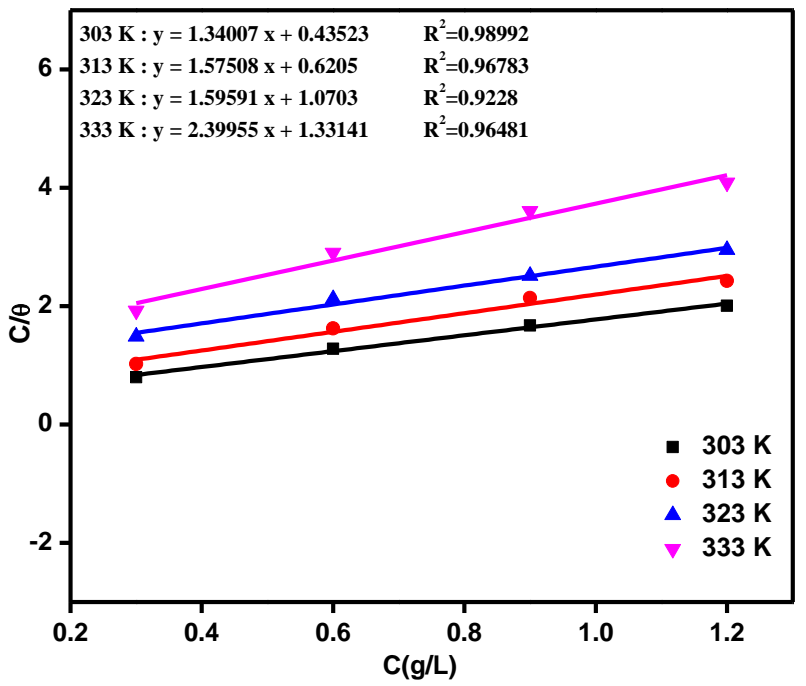

Fig. 4 Langmuir adsorption isotherm for aluminium corrosion in $1 \mathrm{M} \mathrm{NaOH}$ the absence and the presence of various concentrations $(\mathrm{g} / \mathrm{L})$ of DILE at different temperatures. 
Table 3. Calculated values of activation energy $\left(E_{a}\right)$ and free energy of adsorption $\left(\Delta \mathrm{G}^{\circ}{ }_{\text {ads }}\right)$ for aluminum in the absence and presence of the best concentration (1200 ppm) of DILE in $1 \mathrm{M} \mathrm{NaOH}$ solution.

\begin{tabular}{|c|c|c|c|c|c|c|c|}
\hline \multirow{3}{*}{ System } & \multicolumn{3}{|c|}{$E_{a}(\mathrm{~kJ} / \mathrm{mol})$} & \multicolumn{4}{|c|}{$-\Delta \mathrm{G}_{\text {ads }}^{\circ}(\mathrm{kJ} / \mathrm{mol})$} \\
\hline & \multicolumn{3}{|c|}{ Temperature $(\mathrm{K})$} & \multicolumn{4}{|c|}{ Temperature (K) } \\
\hline & $303-313$ & 313-323 & 323-333 & 303 & 313 & 323 & 333 \\
\hline Blank & 49.31 & 37.19 & 20.07 & - & - & - & - \\
\hline $\begin{array}{c}1200 \mathrm{ppm} \text { of } \\
\text { DILE }\end{array}$ & 66.59 & 50.50 & 36.74 & 12.21 & 11.69 & 10.60 & 10.33 \\
\hline
\end{tabular}

the blank solution and the optimum concentration of the inhibitor (1200 ppm) are shown in Table 4. From Table 4, it is very clear that the value of $\Delta H$ and $\Delta S$ are higher in the presence of DILE than blank solution.

Table 4. Calculated values of entropy of adsorption $(\triangle S)$ and enthalpy of adsorption $(\Delta H)$ for aluminium in the absence and presence of the best concentration (1200 ppm) of DILE.

\begin{tabular}{lll}
\hline Concentration & $\Delta S\left(\mathrm{JK}^{-1} \mathrm{M}^{-1}\right)$ & $\Delta H\left(\mathrm{~kJ} \mathrm{~mol}^{-1}\right)$ \\
\hline Blank & -75.04 & 34.41 \\
$1200 \mathrm{ppm}$ & -31.31 & 49.94 \\
\hline
\end{tabular}

The higher value of $E_{a}$ of the inhibitor solution compared to the blank solution indicates that the presence of DILE reduces the corrosion rate by raising the energy barrier for the corrosion process. It indicates that the adsorption of DILE on the surface of aluminium occurs by electrostatic interactions or physisorption mechanisms. The positive value of $\Delta H$ implies that the adsorption of DILE on the surface of aluminium is accompanied by the absorption of heat energy and hence, it is an endothermic process. ${ }^{[30]}$ The values of $\Delta S$ in the absence and presence of DILE are negative, which indicates that the activated complex in the rate-determining step represents an association rather than dissociation, which means that a decrease in disordering occurs ongoing from reactants to activated complex. ${ }^{[12,17,35,36]}$

\subsection{Adsorption isotherm}

Corrosion inhibition by DILE is believed to occur by the adsorption of the inhibitor molecules on the metal surface. The molecular structure and electronic properties of the inhibitor molecules determine the nature of their interaction with the metal surface. A suitable adsorption isotherm can provide information about the metal-inhibitor interaction. The degree of surface coverage values is calculated from the weight loss measurements in the temperature range of 303-333 K, which are used to determine the adsorption characteristics. The adsorption of this compound on the aluminium surface made a barrier for mass and charge transfer. This situation leads to the protection of the Al-surface from the aggressive ions of the alkaline solution. The degree of protection increased with increasing the surface coverage by the adsorbed molecules. As the DILE concentration increased, the number of adsorbed molecules on the surface also increased. Langmuir adsorption isotherm is found to fit well with the obtained experimental data and it can be expressed as Equation (11):[37]

$$
\frac{C}{\theta}=\frac{1}{K_{a d s}}+C
$$

where $C=$ concentration of the inhibitor in $\mathrm{g} / \mathrm{L}, \theta=$ degree of surface coverage, and $K_{a d s}=$ equilibrium constant of the adsorption process.

The plots of $C / \theta$ vs $C$ (Fig. 4) give a straight line and all the regression coefficients are very close to one, which indicates that the adsorption of organic molecules of DILE on the aluminium surface obeys Langmuir adsorption isotherm. The reciprocal of the intercept values obtained from the plot gives the adsorption constant $\left(K_{a d s}\right)$, which is related to the standard free energy of adsorption $\left(\Delta G_{a d s}\right)$ with Equation(12): ${ }^{[38]}$

$$
\Delta G_{\text {ads }}=-R T \ln \left(55.5 \times K_{\text {ads }}\right)
$$

where 55.5 is the concentration of water in solution in mol L${ }^{1}, R$ is the universal gas constant, and $T$ is the absolute temperature.

The calculated values of $\left(\Delta G^{\circ}{ }_{a d s}\right)$ are shown in Table 3. From this table, it is evident that all the free energy values are negative indicating the spontaneous adsorption of DILE on the aluminium surface and the range of free energy values is less than $-20 \mathrm{~kJ} \mathrm{~mol}^{-1}$ indicating that the nature of adsorption is physical for DILE in an alkaline medium. ${ }^{[39,40]}$

\subsection{Electrochemical polarization studies}

When an electrode is polarized to sufficiently large potentials, both in the anodic and cathodic directions, a linear relationship exists between $E$ and $\log I$. The regions, where such a relationship is valid, are called Tafel regions. When aluminium is dipped in the electrolyte, an equilibrium is set up with the anodic and cathodic currents being equal to each other. The application of an electromotive force results in the shifting of the equilibrium, polarizing the metal in the anodic or cathodic directions. The cathodic and anodic polarization curves for aluminium in $1 \mathrm{M} \mathrm{NaOH}$ in the absence and presence of different concentrations of DILE are shown in Fig. 5.

The potentiodynamic polarization parameters such as $E_{c o r r}$, $I_{\text {corr }}$, and Tafel slopes $\left(\beta_{\mathrm{c}}\right.$ and $\left.\beta_{\mathrm{a}}\right)$ are obtained by the extrapolation of Tafel lines using EC lab software, which are given in Table 5. The cathodic and anodic curves are shifted down in presence of the inhibitor, and the corrosion current density is much lower for inhibitor solution with different 
concentrations of DILE compared to the blank solution. This implies that the presence of DILE molecules in $\mathrm{NaOH}$ reduces the corrosion rate of aluminium when compared to the blank solution, thereby confirming the inhibitive nature of DILE.

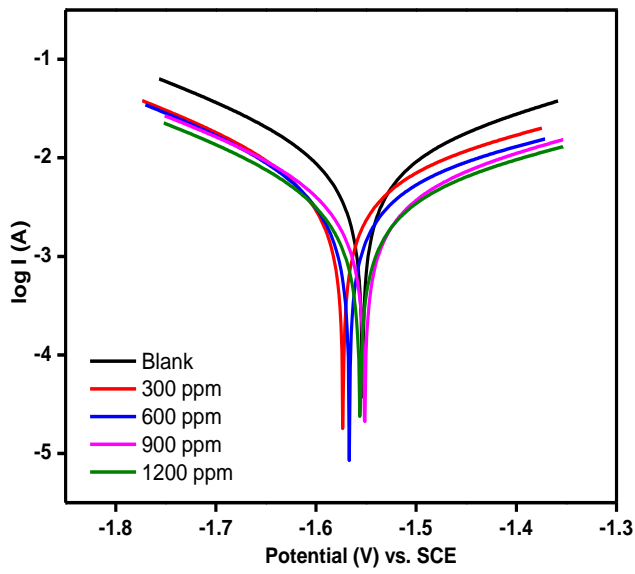

Fig. 5 Potentiodynamic polarization curves for aluminium in $1 \mathrm{M}$ $\mathrm{NaOH}$ in the absence and presence of various concentrations of DILE.

Table 5. Potentiodynamic polarization parameters for aluminium in $1 \mathrm{M} \mathrm{NaOH}$ in the absence and presence of various concentrations of DILE.

\begin{tabular}{|c|c|c|c|c|c|}
\hline $\begin{array}{c}\text { DILE } \\
\text { Concentration }\end{array}$ & $\begin{array}{l}I_{\text {corr }} \\
(\mathrm{mA})\end{array}$ & $E_{\text {corr }}(\mathrm{mV})$ & $\begin{array}{c}\beta_{\mathrm{c}} \\
(\mathrm{mV})\end{array}$ & $\begin{array}{c}\beta_{\mathrm{a}} \\
(\mathrm{mV})\end{array}$ & IE\% \\
\hline Blank & 12.0200 & -1553.68 & 272.7 & 373.5 & - \\
\hline $300 \mathrm{ppm}$ & 7.5717 & -1573.18 & 274.5 & 439.7 & 37.0 \\
\hline 600 ppm & 6.4737 & -1566.81 & 269.3 & 474.4 & 46.1 \\
\hline $900 \mathrm{ppm}$ & 5.5247 & -1551.39 & 279.9 & 420.0 & 54.0 \\
\hline $1200 \mathrm{ppm}$ & 4.8970 & -1556.04 & 281.2 & 447.6 & 59.3 \\
\hline
\end{tabular}

The corrosion of aluminium in an alkaline medium is said to occur by the action of local cells: partial anodic and cathodic reactions occurring simultaneously on the metal surface. It has been reported that the anodic dissolution of aluminium in the alkaline medium takes place through the stepwise addition of surface hydroxyl species to the electrochemically formed $\mathrm{Al}(\mathrm{OH})_{3}$ film resulting in the dissolution of the film. The partial anodic reaction taking place during the corrosion of aluminium in an alkaline medium is represented as ${ }^{[41,42]}$

$$
\mathrm{Al}+4 \mathrm{OH}^{-} \leftrightarrow \mathrm{Al}(\mathrm{OH})_{4}^{-}+3 e^{-}
$$

The electrons produced during the partial anodic reactions are immediately consumed during the partial cathodic reaction during the corrosion process, the equation can be represented $\operatorname{as}^{[43]}$

$$
2 \mathrm{H}_{2} \mathrm{O}+2 e^{-} \leftrightarrow \mathrm{H}_{2}+2 \mathrm{OH}^{-}
$$

According to the literature, if the $E_{\text {corr }}$ value for the inhibited system is less than $85 \mathrm{mV}$ with respect to the uninhibited system then the inhibitor, DILE can be regarded as an anodic or cathodic type (mixed type). ${ }^{[44]}$ Since there is no noticeable shift in $E_{\text {corr }}$ values, hence it can be considered that DILE as a mixed-type inhibitor affects both the anodic and cathodic corrosion processes. ${ }^{[45]}$

\subsection{AC-impedance studies}

The corrosion behavior of aluminium in the absence and presence of various concentrations of DILE was studied by AC-Impedance studies and the impedance spectra obtained were recorded as Nyquist plots, shown in Fig. 6. On observing the plots obtained, 2 semi-circle loops or time constants are visible: (a) a capacitive loop at high frequencies, (b) an inductive loop at medium frequencies and (c) a second capacitive loop at low frequencies. The size of the semi-circle depends on the anodic potential. The diameter of the capacitive loop at high frequencies and the diameter of the inductive loop at medium frequencies increase with anodic potential. ${ }^{[46]}$ While studying the corrosion behavior of aluminium in an alkaline medium, it is necessary to consider the presence of the native surface oxide film. When aluminium is dipped in the electrolyte, two interfaces can be described: metal/oxide interface and oxide/electrolyte interface. The first capacitive loop corresponds to the charge transfer process and the interfacial reactions at the metal/oxide/electrolyte interface. The $\mathrm{Al}^{+}$ions formed at the metal/oxide interface migrate through the oxide layer to the oxide/solution interface due to a high electric field strength, where they get oxidized to $\mathrm{Al}^{3+}$. The inductive loop can be attributed to the relaxation of the adsorbed intermediates $\left(\mathrm{OH}^{-}\right.$ads $)$to the oxide layer of the metal surface. The second capacitive loop in the low frequency could be assigned to the dissolution of the oxide layer. ${ }^{[47,48]}$

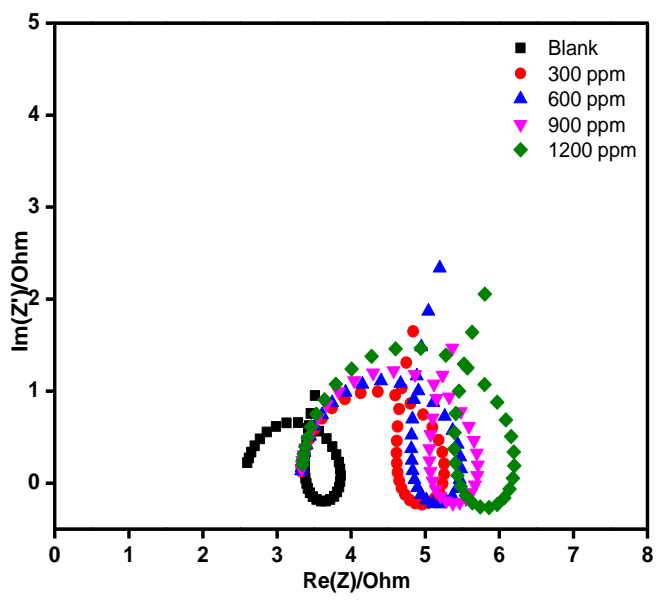

Fig. 6 Nyquist plots for aluminium in $1 \mathrm{M} \mathrm{NaOH}$ in the absence and the presence of various concentrations of DILE.

Table 6 shows that the impedance parameters for aluminium corrosion were obtained in the absence and presence of various concentrations of the inhibitor. The corrosion rate of metal in a medium is inversely related to $R_{c t}$ and directly to $C_{d l}$. A decrease in $C_{d l}$ values can be attributed to the decrease in the local dielectric constant or increase in thickness of the electrical double layer suggesting the inhibiting action on the metal/solution interface. It can be observed that the $R_{c t}$ value increases and the $C_{d l}$ value decrease with an increase in DILE concentration. This implies that a higher concentration of DILE is favorable for corrosion inhibition. 
Table 6. Impedance parameters for aluminium corrosion in $1 \mathrm{M}$ $\mathrm{NaOH}$ in the absence and the presence of various concentrations of DILE.

\begin{tabular}{ccccc}
\hline $\begin{array}{c}\text { DILE } \\
\text { Conc. }\end{array}$ & $\begin{array}{c}\mathrm{R}_{s} \\
(\mathrm{Ohm})\end{array}$ & $\begin{array}{c}\mathrm{R}_{c t} \\
(\mathrm{Ohm})\end{array}$ & $\begin{array}{c}\mathrm{C}_{d l} \\
(\mu \mathrm{F})\end{array}$ & $\begin{array}{c}\mathrm{IE} \\
(\%)\end{array}$ \\
\hline Blank & 2.563 & 0.80 & 7.03 & -- \\
$300 \mathrm{ppm}$ & 3.327 & 1.27 & 4.02 & 37.2 \\
$600 \mathrm{ppm}$ & 3.329 & 1.46 & 4.19 & 45.4 \\
$900 \mathrm{ppm}$ & 3.331 & 1.68 & 2.79 & 52.6 \\
$1200 \mathrm{ppm}$ & 3.341 & 2.00 & 2.35 & 60.2 \\
\hline
\end{tabular}

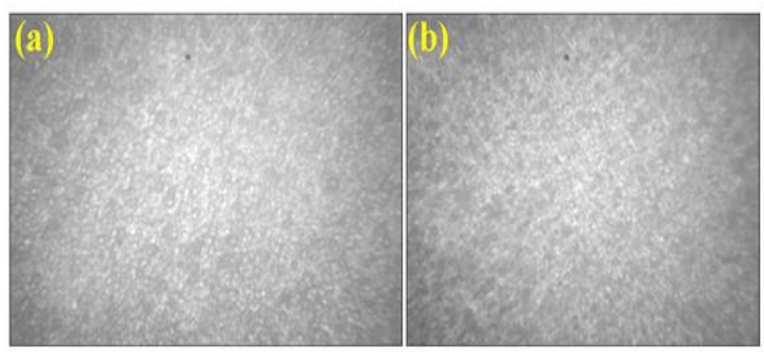

Fig. 7 Surface images of a) aluminium coupon immersed in $1 \mathrm{M}$ $\mathrm{NaOH}$, and b) aluminium coupon immersed in DILE solution (1.2 $\mathrm{g} / \mathrm{L})$.

\subsection{Metallurgical microscopy studies}

Surface modification during the corrosion of aluminium in the absence and the presence of the best concentration $(1.2 \mathrm{~g} / \mathrm{L})$ of DILE is shown in Fig. 7. On immersion in the blank solution of $1 \mathrm{M} \mathrm{NaOH}$, the polished surface of the aluminium coupon undergoes vigorous changes due to corrosion. Interestingly, the surface of the coupon immersed in $1.2 \mathrm{~g} / \mathrm{L}$ of DILE appears to be less damaged than the surface of the coupon immersed in the blank solution. This confirms the inhibitory action of DILE.

\subsection{Corrosion inhibition mechanism}

It is found that DILE gets adsorbed on the surface of aluminium by a physisorption mechanism. Studying the chemical constituents present in an aqueous solution, DILE will help to understand its inhibition action. The leaves of Derris indica are enriched with various bioactive components a)<smiles>COc1cc2c(=O)cc(-c3ccccc3)oc2c2ccoc12</smiles>

b)<smiles>COc1c(-c2ccccc2)oc2c(ccc3occc32)c1=O</smiles>

d)

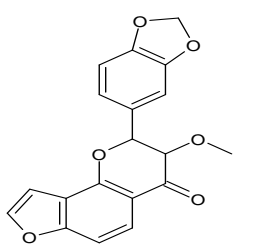

Fig. 8 Structure of a) Kanjone, b) Karanjin, c) Karanjochromene and d) Pongapin. such as flavonoids, terpenoids, alkaloids, etc. Some of the phytoconstituents of Derris indica leaves including Karanjin, Kanjone, Karanjochromene, and Pongapin ${ }^{[49]}$ may perhaps play a key role in the inhibition of the corrosion process, and their chemical structures are illustrated in Fig. 8. The adsorption isotherm study confirmed that the adsorbed inhibitor molecules over the metal surface form a protective barrier between the corrosive environment and the metal surfaces. ${ }^{[50]}$ These bioactive molecules consist of aromatic $\pi$ electron systems with heteroatoms such as $\mathrm{O}$, through which they can get adsorbed on the metal surface and form a protective film and hence inhibit the corrosion process.

\section{Conclusion}

From the above studies, it is observed that the inhibition action of DILE on aluminium corrosion has a maximum inhibition efficiency of $60.2 \%$. The inhibition efficiency increases with an increase in the concentration of DILE and the best concentration of DILE is found to be $1.2 \mathrm{~g} / \mathrm{L}$. The potentiodynamic polarization studies indicate that DILE behaves as a mixed type of corrosion inhibitor since there is no significant shift in $E_{c o r r}$ values. The adsorption of the inhibitor molecules on the aluminium surface obeys Langmuir adsorption isotherm and the nature of the adsorption is found to be physisorption since $-\Delta \mathrm{G}^{\circ}$ ads is found to be less than -20 $\mathrm{kJ} / \mathrm{mol}$. The metallurgical microscopic study further supports the inhibitory action of DILE since the metal surface dipped in $1 \mathrm{M} \mathrm{NaOH}$ is found to have suffered more pitting corrosion damage than the metal surface dipped with the inhibitor system. The constituents present in DILE contain aromatic heterocyclic systems, which confirm the inhibitory action. Thus, DILE serves as an efficient inhibitor for the corrosion of aluminium in an alkaline medium.

\section{Acknowledgment}

The authors are very grateful to Central Instrumentation Facility (CIF), Pondicherry University, Puducherry for providing the instrumentation facilities.

\section{Conflict of interest}

There are no conflicts to declare.

\section{Supporting information}

Not applicable

\section{References}

[1] N. Chaubey, V. K. Singh, M. A. Quraishi, Electrochemical approach of Kalmegh leaf extract on the corrosion behavior of aluminium alloy in alkaline solution, International Journal of Industrial Chemistry, 2017, 8, 75-82, doi: 10.1007/s40090-0160103-y.

[2] L. Wang, W. Wang, G. Yang, D. Liu, J. Xuan, H. Wang, M. K. H. Leung, F. Liu, A hybrid aluminum/hydrogen/air cell system, International Journal of Hydrogen Energy, 2013, 38, 1480114809, doi: 10.1016/j.ijhydene.2013.09.036. 
[3] N. Chaubey, D. K. Yadav, V. K. Singh, M. A. Quraishi, A comparative study of leaves extracts for corrosion inhibition effect on aluminium alloy in alkaline medium, Ain Shams Engineering Journal, 2017, 8, 673-682, doi: 10.1016/j.asej.2015.08.020.

[4] D Féron, Corrosion Behaviour and Protection of Copper and Aluminium Alloys in Seawater, Woodhead Publishing, first edition, 2007, 145-155.

[5] R. W. Revie, H. H. Uhlig, Corrosion and Corrosion Control. Hoboken, New Jersey, USA, John Wiley \& Sons, Inc., 2008, doi: 10.1002/9780470277270.

[6] E. E. Oguzie, Corrosion inhibition of aluminium in acidic and alkaline media by Sansevieria trifasciata extract, Corrosion Science, 2007, 49, 1527-1539, doi: 10.1016/j.corsci.2006.08.009. [7] N. Santhini, T. Jeyaraj, The inhibition effect of [3-(4-hydroxy3-methoxy-phenyl)-1-(2-hydroxyPhenyl-propenone] on the corrosion of the aluminium in alkaline medium, Archives of Applied Science Research, 2012, 4, 3550-3556.

[8] S. Edrah, S. K. Hasan, Studies on Thiourea Derivatives as Corrosion Inhibitor for Aluminum in Sodium Hydroxide Solution, Journal of Applied Sciences Research, 2010, 6, 1045-1049.

[9] M. Abdallah, O. A. Hazazi, A. Fawzy, S. El-Shafei, A. S. Fouda, Influence of N-thiazolyl-2-cyanoacetamide derivatives on the corrosion of aluminum in $0.01 \mathrm{M}$ sodium hydroxide, Protection of Metals and Physical Chemistry of Surfaces, 2014, 50, 659-666, doi: 10.1134/s2070205114050025.

[10] P. R. Kumari, J. Nayak, A. N. Shetty, 3-Methyl-4-amino-5mercapto-1,2,4-triazole as corrosion inhibitor for $6061 \mathrm{Al}$ alloy in $0.5 \mathrm{M}$ sodium hydroxide solution, Journal of Coatings Technology and Research, 2011, 8, 685, doi: 10.1007/s11998011-9341-2.

[11] S. Abd El-Rehim, H. Hassan, M. Deyab, A. Abd El Moneim, Experimental and theoretical investigations of adsorption andInhibitive properties of tween 80 on corrosion of aluminum alloy(A5754) in alkaline media, Zeitschrift Für Physikalische Chemie, 2016, 230, 67-78, doi: 10.1515/zpch-2015-0614.

[12] S. Geetha, S. Lakshmi, K. Bharathi, Solanum trilobatum as a green inhibitor for aluminium corrosion in alkaline medium, Journal of Chemical and Pharmaceutical Research, 2013, 5, 195204.

[13] A. Sirajun Nisa, M. F. Mohamed, A. Subramania, B. R. Venatraman, Green Approach to Corrosion Inhibition of Aluminium By Senna Auriculata Leaves Extract In $1 \mathrm{~N} \mathrm{NaOH}$ Solution, International Journal of Science Engineering and Advance Technology, 2014, 2, 23-31.

[14] O. K. Abiola, J. O. E. Otaigbe, The effects of Phyllanthus amarus extract on corrosion and kinetics of corrosion process of aluminum in alkaline solution, Corrosion Science, 2009, 51, 2790-2793, doi: 10.1016/j.corsci.2009.07.006.

[15] A. Sirajunnisa, M. F. Mohamed, A. Subramania, B. R. Venkatraman, The inhibitive effect of Ziziphus jujuba leaves extract on the alkaline corrosion of aluminium, European Journal of Applied Sciences and Technology, 2014, 1, 23-31.

[16] S. A. Umoren, I. B. Obot, L. E. Akpabio, S. E. Etuk, Adsorption and corrosive inhibitive properties of Vigna unguiculata in alkaline and acidic media, Pigment \& Resin Technology, 2008, 37, 98-105, doi: 10.1108/03699420810860455. [17] N. Chaubey, Savita, V. K. Singh, M. A. Quraishi, Corrosion inhibition performance of different bark extracts on aluminium in alkaline solution, Journal of the Association of Arab Universities for Basic and Applied Sciences, 2017, 22, 38-44.

[18] M. Abdallah, E. M. Kamar, A. Y. El-Etre, S. Eid, Gelatin as corrosion inhibitor for aluminum and aluminum silicon alloys in sodium hydroxide solutions, Protection of Metals and Physical Chemistry of Surfaces, 2016, 52, 140-148, doi: 10.1134/s2070205116010020.

[19] I. B. Obot, N. O. Obi-Egbedi, Ipomoea involcrata as an ecofriendly inhibitor for aluminium in alkaline medium, Portugaliae Electrochimica Acta, 2009, 27, 517-524, doi: 10.4152/pea.200904517.

[20] S. Ambrish, M. A. Quraishi, Azwain (Trachyspermum copticum) seed extract as an efficient corrosion Inhibitor for Aluminium in $\mathrm{NaOH}$ solution, Research Journal of Recent Sciences, 2012, 1, 57-61.

[21] K. Xhanari, M. Finšgar, M. Knez Hrnčič, U. Maver, Ž. Knez, B. Seiti, Green corrosion inhibitors for aluminium and its alloys: a review, RSC Advances, 2017, 7, 27299-27330, doi: 10.1039/c7ra03944a.

[22] M. Abdallah, E. M. Kamar, S. Eid, A. Y. El-Etre, Animal glue as green inhibitor for corrosion of aluminum and aluminumsilicon alloys in sodium hydroxide solutions, Journal of Molecular Liquids, 2016, 220, 755-761, doi: 10.1016/j.molliq.2016.04.062.

[23] S. Eid, M. Abdallah, E. M. Kamar, A. Y. El-Etre, Corrosion inhibition of aluminum and aluminum silicon alloys in sodium hydroxide solutions by methyl cellulose, Journal of Materials and Environmental Science, 2015, 6, 892-901.

[24] S. S. Shivakumar, K. N. Mohana, D. M. Gurudatt, Inhibition performance and adsorption behavior of spinacia oleracea leaves extracts on mild steel corrosion in hydrochloric acid medium, Chemical Science Transactions, 2012, 2, 163-175, doi: $10.7598 /$ cst2013.302.

[25] O. K. Abiola, J. O. E. Otaigbe, O. J. Kio, Gossipium hirsutum L. extracts as green corrosion inhibitor for aluminum in $\mathrm{NaOH}$ solution, Corrosion Science, 2009, 51, 1879-1881, doi: 10.1016/j.corsci.2009.04.016.

[26] A. Singh, I. Ahamad, M. A. Quraishi, Piper longum extract as green corrosion inhibitor for aluminium in $\mathrm{NaOH}$ solution, Arabian Journal of Chemistry, 2016, 9, S1584-S1589, doi: 10.1016/j.arabjc.2012.04.029.

[27] S. Perumal, S. Muthumanickam, A. Elangovan, R. Karthik, R. S. Kannan, K. K. Mothilal, Bauhinia tomentosa leaves extract as green corrosion inhibitor for mild steel in $1 \mathrm{M} \mathrm{HCl}$ medium, Journal of Bio- and Tribo-Corrosion, 2017, 3, 13, doi: 10.1007/s40735-017-0072-5.

[28] S. Ghareba, S. Omanovic, Interaction of 12aminododecanoic acid with a carbon steel surface: towards the development of 'green' corrosion inhibitors, Corrosion Science, 2010, 52, 2104-2113, doi: 10.1016/j.corsci.2010.02.019.

[29] H. Tian, W. Li, K. Cao, B. Hou, Potent inhibition of copper 
corrosion in neutral chloride media by novel non-toxic thiadiazole derivatives, Corrosion Science, 2013, 73, 281-291, doi: 10.1016/j.corsci.2013.04.017.

[30] F. El-Hajjaji, M. Messali, A. Aljuhani, M. R. Aouad, B. Hammouti, M. E. Belghiti, D. S. Chauhan, M. A. Quraishi, Pyridazinium-based ionic liquids as novel and green corrosion inhibitors of carbon steel in acid medium: Electrochemical and molecular dynamics simulation studies, Journal of Molecular Liquids, 2018, 249, 997-1008, doi: 10.1016/j.molliq.2017.11.111. [31] S. A. Umoren, E. E. Ebenso, Studies of the anti-corrosive effect of Raphia hookeri exudate gum-halide mixtures for aluminium corrosion in acidic medium, Pigment \& Resin Technology, 2008, 37, 173-182, 10.1108/03699420810871020.

[32] N. Chaubey, Savita, V. K. Singh, M. A. Quraishi, Corrosion inhibition performance of different bark extracts on aluminium in alkaline solution, Journal of the Association of Arab Universities for Basic and Applied Sciences, 2017, 22, 38-44, doi: 10.1016/j.jaubas.2015.12.003.

[33] C. Verma, L. O. Olasunkanmi, E. E. Ebenso, M. A. Quraishi, I. B. Obot, Adsorption behavior of glucosamine-based, pyrimidine-fused heterocycles as green corrosion inhibitors for mild steel: experimental and theoretical studies, The Journal of Physical Chemistry C, 2016, 120, 11598-11611, doi: 10.1021/acs.jpcc.6b04429.

[34] R. Haldhar, D. Prasad, A. Saxena, R. Kumar, Experimental and theoretical studies of Ficus religiosa as green corrosion inhibitor for mild steel in $0.5 \mathrm{M} \mathrm{H}_{2} \mathrm{SO}_{4}$ solution, Sustainable Chemistry and Pharmacy, 2018, 9, 95-105, doi: 10.1016/j.scp.2018.07.002.

[35] R. Hassan, I. Zaafarany, Kinetics of corrosion inhibition of aluminum in acidic media by water-soluble natural polymeric pectates as anionic polyelectrolyte inhibitors, Materials, 2013, 6, 2436-2451, doi: 10.3390/ma6062436.

[36] S. Geetha, S. Lakshmi, K. Bharathi, Corrosion Inhibition of Aluminium in Alkaline Medium using Vitex Negundo Leaves Extract, International journal of advanced scientific and technical research, 2013, 3, 258-268.

[37] M. Tourabi, K. Nohair, M. Traisnel, C. Jama, F. Bentiss, Electrochemical and XPS studies of the corrosion inhibition of carbon steel in hydrochloric acid pickling solutions by 3, 5-bis(2thienylmethyl)-4-amino-1, 2, 4-triazole, Corrosion Science, 2013, 75, 123-133, doi: 10.1016/j.corsci.2013.05.023.

[38] V. Srivastava, J. Haque, C. Verma, P. Singh, H. Lgaz, R. Salghi, M. A. Quraishi, Amino acid based imidazolium zwitterions as novel and green corrosion inhibitors for mild steel: experimental, DFT and MD studies, Journal of Molecular Liquids, 2017, 244, 340-352, doi: 10.1016/j.molliq.2017.08.049. [39] M. Benabdellah, A. Tounsi, K. F. Khaled, B. Hammouti, Thermodynamic, chemical and electrochemical investigations of 2-mercapto benzimidazole as corrosion inhibitor for mild steel in hydrochloric acid solutions, Arabian Journal of Chemistry, 2011, 4, 17-24, doi: 10.1016/j.arabjc.2010.06.010.

[40] S. Rajendran, C. Thangavelu, A. Angamuthu, S. Jayakumar, Inhibition of corrosion of aluminium in alkaline medium by glutaric acid in conjunction with zinc sulphate and diethylene triamine penta (Methylene phosphonic acid), Archives of Applied Science Research, 2013, 5, 202-212.

[41] B. A. Abd-El-Nabey, A. M. Abdel-Gaber, M. E. Said Ali, E. Khamis, S. El-Housseiny, International Journal of Electrochemical Science, 2012, 7, 11811-11826.

[42] P. Deepa, R. Padmalatha, Corrosion behaviour of 6063 aluminium alloy in acidic and in alkaline media, Arabian Journal of Chemistry, 2017, 10, S2234-S2244, doi: 10.1016/j.arabjc.2013.07.059.

[43] G. T. Burstein, C. Liu, The cathodic reaction during repassivation of aluminium in open circuit, Corrosion Science, 1995, 37, 1151-1162, doi: 10.1016/0010-938x(95)00023-d.

[44] E. S. Ferreira, C. Giacomelli, F. C. Giacomelli, A. Spinelli, Evaluation of the inhibitor effect of 1-ascorbic acid on the corrosion of mild steel, Materials Chemistry and Physics, 2004, 83, 129-134, doi: 10.1016/j.matchemphys.2003.09.020.

[45] P. Parthipan, L. Cheng, A. Rajasekar, Glycyrrhiza glabra extract as an eco-friendly inhibitor for microbiologically influenced corrosion of API 5LX carbon steel in oil well produced water environments, Journal of Molecular Liquids, 2021, 333, 115952, doi: 10.1016/j.molliq.2021.115952.

[46] H. J. W. Lenderink, M. V. D. Linden, J. H. W. De Wit, Corrosion of aluminium in acidic and neutral solutions, Electrochimica Acta, 1993, 38, 1989-1992, doi: 10.1016/00134686(93)80329-x.

[47] C. M. A. Brett, The application of electrochemical impedance techniques to aluminium corrosion in acidic chloride solution, Journal of Applied Electrochemistry, 1990, 20, 10001003, doi: 10.1007/bf01019579.

[48] M. Metikoš-Huković, R. Babić, Z. Grubač, The study of aluminium corrosion in acidic solution with nontoxic inhibitors, Journal of Applied Electrochemistry, 2002, 32, 35-41, doi: 10.1023/A:1014265407060.

[49] P. C. Chikezie, C. O. Ibegbulem, F. N. Mbagwu, Bioactive principles from medicinal plants, Research Journal of Phytochemistry, 2015, 9, 88-115, doi: 10.3923/rjphyto.2015.88.115.

[50] P. Parthipan, M. S. AlSalhi, S. Devanesan, A. Rajasekar, Evaluation of Syzygium aromaticum aqueous extract as an ecofriendly inhibitor for microbiologically influenced corrosion of carbon steel in oil reservoir environment, Bioprocess and Biosystems Engineering, 2021, 44, 1441-1452, doi: 10.1007/s00449-021-02524-8.

Publisher's Note: Engineered Science Publisher remains neutral with regard to jurisdictional claims in published maps and institutional affiliations. 